\title{
ANÁLISE DOS ESPAÇOS URBANOS DESTINADOS AO ASSENTAMENTO DE HABITAÇÃO DE INTERESSE SOCIAL: POLÍTICAS, TEMPORALIDADES E EVIDÊNCIAS SOCIO-ESPACIAIS
}

\author{
Giullia Junqueira Pessanha ${ }^{1}$, Guilherme Gonçalves Pereira ${ }^{1}$, João Pedro da Mota Madalena ${ }^{1}$, \\ Júlia Cândido da Penha Regis ${ }^{1}$, Nathália Aline Rangel Marinho ${ }^{1}$, Lara de Almeida Coelho \\ Gimenes $^{1}$, Ronald Fonseca Ribeiro Mata ${ }^{1}$ \& Mário Márcio Santos Queiroz ${ }^{2 *}$
}

\section{RESUMO}

PESSANHA ,G. J.; PEREIRA, G. G. ; MADAlENA, J. P. M.; REGIS, J. C. P. MARINHO, N. A. R.; GIMENES, L. A. C.; MATA, R. F. R.; QUEIROZ, M. M. S. Análise dos Espaços Urbanos Destinados ao Assentamento de Habitação de Interesse Social: Políticas, Temporalidades e Evidências Socio-Espaciais. Perpectivas Online: Humanas \& Sociais Aplicadas, v.7, n.19, p.6-9, 2017.

O presente trabalho tem como objetivo uma reflexão sobre a inserção dos espaços destinados as habitações de interesse social na cidade consolidada, sendo levantadas questões como a favelização de parte destes territórios urbanos. Este texto se insere na área das ciências sociais aplicadas, tendo seu tema focado na inserção da favela na cidade consolidada, onde ela se situa mas não se encontra inclusa, por estar fora dos "padrões" de legalidade urbanística. Configura-se pela ação de autoconstrução pelos próprios moradores e no descumprimento de regras básicas de planejamento urbanístico, tais como arruamento, calçadas, afastamentos, entre tantos outros. Percebe-se a não inserção da favela na cidade e a consequente exclusão sócio-espacial e configurada pela estigmatização social direcionada à marginalização dos moradores ali assentados.

Palavras-chave: Arquitetura; Espacialização Urbana; Habitação de Interesse Social; Programas Habitacionais; Urbanismo. 


\begin{abstract}
The present work aims to reflect on the insertion of spaces destined to housing of social interest in the consolidated city, being raised issues such as favellization of part of these urban territories. This text is inserted in the area of applied social sciences, with its theme focused on the insertion of the favela in the consolidated city, where it is situated but is not included because it is outside the "standards" of urban legality. It is

configured by the self-construction action of the residents themselves and in the non-compliance with basic rules of urban planning, such as streets, sidewalks, separations, among many others. It is possible to perceive the non-insertion of the favela in the city and the consequent socio-spatial exclusion and configured by the social stigmatization directed to the marginalization of the residents settled there.
\end{abstract}

Keywords: Architecture; Urban Spacing; Housing of Social Interest; Housing Programs; Urbanism.

\footnotetext{
${ }^{1}$ Acadêmicos de Arquitetura e Urbanismo ISECENSA- Institutos Superiores de Ensino do CENSA - ISECENSA - Rua Salvador Correa, 139, Centro, Campos dos Goytacazes, RJ, CEP: 28035-310, Brasil;

${ }^{2}$ Institutos Superiores de Ensino do CENSA - ISECENSA - Núcleo de Estudos da Habitação- Rua Salvador Correa, 139 , Centro, Campos dos Goytacazes, RJ, CEP: 28035-310, Brasil;

(*)e-mail: mariom.queiroz@gmail.com

Data de chegada: 19/04/2017 Aceito para publicação: 09/06/2017
} 


\section{INTRODUÇÃO}

Favelas são espaços denegridos nas sociedades urbanas brasileiras, tanto pelo conceito social quanto espacial. Desta forma, na dicotomia percebida no contexto entra espaços urbanos de cunho formal e informal, se estabelecem as condições sócio-espaciais divergentes e geradas pelas (3) três abordagens citadas neste artigo: a gestão política que se articulou nas diversas etapas temporais, notadamente ao longo do século XX e os resultados da inoperância urbana na conexão estruturante do território carioca. O objeto de estudo deste trabalho se baseia na interação acadêmica desenvolvida na Favela Santa Marta, na cidade do Rio de Janeiro.

Neste contexto, a concepção moral direcionada à caracterização de "favela" e "favelado" está ligado ao estigma desenhado na cidade carioca, historicamente voltado ao espaço urbano ocupado pelos moradores favelizados. Torna-se uma concepção pejorativa enquanto espaço estigmatizante e, com o tempo, vai adquirindo uma ideia de depreciação, conjugada com as práticas construtivas aplicadas, que configuram uma série de mitos voltados para pobreza, violência e criminalidade (FREIRE, 2008).

\section{METODOLOGIA}

Em relação à proposta metodológica abordada, espera-se a observação e análise conceitual das condições habitacionais e de moradia, bem como dos espaços coletivos. Além dos equipamentos urbanos já existentes, dentre os quais pequenas praças, campos de futebol e unidades de saúde, a presença destes requisitos permite direcionar diretrizes positivas à vida comunitária para todos que ali residem, trazendo benefícios e contribuindo para a melhoria qualitativa do modus-vivendi de seus habitantes. São requisitos importantes que, se subsidiados pela ação do poder público, permitem possibilitar a inserção da favela no espaço urbano objetivado pela recostura sócio-espacial.

Atesta-se nesse ínterim que as medidas de planejamento operacional na localidade, interligadas às práticas de conteúdo projetual visa à integração de áreas favelizadas com os espaços da cidade já consolidados. Este argumento torna-se essencial para mitigar a segregação sócio-espacial encontrada nas cidades atuais, cuja decorrência e problemas torna-se consequência para os distúrbios urbanos observados, principalmente nos grandes centros urbanos.

\section{DESENVOLVIMENTO}

A distância entre os espaços urbanos destinados ao assentamento de habitação social e a cidade, ou seja, a dificuldade em promover a inserção e consideração do espaço urbano como parte integrantes da cidade consolidada tem como ponto de referência a dicotomia das desigualdades geradas por variáveis sóciodemográficas. Determinam-se pelas distintas capacidades financeiras para as diferentes classes sociais que se complementam, como fator de análise social, por exemplo, análise sobre parâmetros de idade, cor, sexo, escolaridade e inserção na estrutura ocupacional. Tais desigualdades acabam gerando segregação e discriminação de segmentos sociais e consequente estruturação de critério seletivo para oferta e distribuição para espaços ocupacionais a serem selecionados nas comunidades. Além dessa questão, há uma estigmatização dos territórios onde tem uma maior concentração de segmentos mais fragilizados economicamente (RIBEIRO E LAGO, 2001).

Na experiência pragmática realizada na comunidade favelizada do Santa Marta, no Rio de Janeiro, teve como atividade a visita técnica onde estiveram presente, aproximadamente o quantitativo de 60 pessoas, entre professores, pesquisadores e alunos das 5 universidades participantes. Promoveram a divisão de áreas de

Persp. online: hum. \& sociais aplicada., Campos dos Goytacazes, 19 (7), 06-09, 2017

seer.perspectivasonline.com.br 
estudos na comunidade com a utilização de levantamento físico e topográfico do espaço favelizado, documento este fornecido pela associação de moradores da localidade. Foram separados setores de centralidade funcional, identificadas nos platôs contíguos aos níveis topográficos onde se situam as estações de parada do Plano Inclinado ou Sistema Funicular. Com isso, o grupo foi dividido em subgrupos, responsáveis pelos setores determinados, com o intuito de promover o levantamento físico da comunidades. Com o mapa disponibilizado, cada grupo identificava suas respectivas casas, verificando quais delas ainda encontram-se edificadas em madeira e, quando possível a realização da medição internas nos compartimentos das moradias, serviriam como ferramenta para a produção da maquete tridimensional.

Com a visita, o grupo de alunos e monitores autores deste artigo identificaram a presença de um razoável quantitativo de moradias edificadas em madeira, sem mínimas condições básicas de habitabilidade. Entretanto, nas entrevistas realizadas com moradores da comunidade, foram identificadas as principais necessidades do local, notadamente a falta de infraestrutura apresentando-se como o principal elemento para melhoria das condições habitacionais. Já para a percepção de espacialidade do local, os moradores apontaram como reclamações mais comuns a falta de equipamentos de lazer e sociabilidade, dentre os quais praças coletivas, espaços de lazer e recreação, mobilidade e acessibilidade.

\section{CONSIDERAÇÕES FINAIS}

O desafio político em relação a integração social do espaço urbano, que pode gerar conflitos frutos dessa superposição entre culturas e territórios, é o mesmo desafio que o Brasil e o Rio de Janeiro têm que enfrentar, superando assim as fronteiras territoriais (BURGOS, 2005).

Espera-se que a interação do corpo discente junto às comunidades informais, ocupações irregulares e favelizadas que necessitem de assessoramento técnico e a consequente argumentação teórica para compreensão de efeitos, consequências e problemas existentes nestas localidades sejam os resultados que este projeto possa promover.

\section{REFERÊNCIAS}

RIBEIRO, Luiz César de Queiroz; DO LAGO, Luciana Corrêa. "A oposição favela-bairro no espaço social do Rio de Janeiro.” São Paulo em Perspectiva. São Paulo, n.1, 2001.p.144-154.

BURGOS, Marcelo Baumann. "Cidade, Territórios e Cidadania." Revista de Ciências Sociais. Rio de Janeiro, n.1,2005. p. 189-222.

DO LAGO, Luciana Corrêa; RIBEIRO, Luiz César de Queiroz. "A divisão favela-bairro no Rio de Janeiro." Caderno Metrópole. São Paulo, n.05, 2001. p 29-46.

FREIRE, Letícia de Luna. "Favela, bairro ou comunidade? Quando uma política urbana torna-se uma política de significados." Dilemas Revista de conflitos e controle. n.2,2008.p.95-144.

Persp. online: hum. \& sociais aplicada., Campos dos Goytacazes, 19 (7), 06-09, 2017

seer.perspectivasonline.com.br 